\title{
Lactose-induced Synchronous Sclerotium Formation in Sclerotium rolfsii and Its Inhibition by Ethanol
}

\author{
By Y. OKON, I. CHET AND Y. HENIS \\ Department of Plant Pathology and Microbiology, The Hebrew University of \\ Jerusalem, Faculty of Agriculture, Rehovot, Israel
}

(Accepted for publication 22 February 1972)

\section{SUMMARY}

Synchronous formation of sclerotia in Sclerotium rolfsii was induced in synthetic media containing glucose $(0.3$ to $\mathrm{I} \cdot 9 \%$ w/v) by adding $0.5 \%(\mathrm{w} / \mathrm{v})$ lactose. Sclerotia were formed after 4 days at the colony margin in a circular band, the width of which was directly related to glucose concentration. Sclerotium formation in media containing glucose, with and without lactose, was completely inhibited by the addition of $2 \%(\mathrm{v} / \mathrm{v})$ ethanol. This inhibition was not affected by iodoacetic acid $\left(5 \times 10^{-5} \mathrm{M}\right)$. Neither lactose nor ethanol was oxidized by the fungus. Oxygen consumption with glucose as substrate was partially inhibited by ethanol but not by lactose. The significance of this system in morphogenetic studies is discussed.

\section{INTRODUCTION}

Sclerotium formation in Sclerotium rolfsii Sacc. on agar plates usually occurs at different times within the colony. Synchronization of formation is essential for the study of structural and biochemical changes preceding and accompanying sclerotium formation.

Nutritional and mechanical factors involved in sclerotium formation were studied by Henis, Chet \& Avizohar-Hershenzon (1965) and by Wheeler \& Waller (1965). According to Chet, Henis \& Mitchell (1966), sclerotium production in Sclerotium rolfsii is prevented by sulphur-containing amino acids and induced by iodoacetic acid. Chet \& Henis (I968) suggested that iodoacetic acid induced sclerotium formation by the inactivation of a hypothetical intracellular repressor. B. E. J. Wheeler (personal communication, I968) found that low concentrations of ethanol interfered with sclerotium formation.

In this paper, a system which induces the synchronous formation of sclerotia in Sclerotium rolfsii is described, together with some inhibitory effects of ethanol on sclerotium formation.

\section{METHODS}

Fungal strain and growth medium. Sclerotium rolfsii Sacc. isolated from sugar beet, was grown on a synthetic medium of Joham (1943) as previously described (Chet et al. I966).

Agar discs $(0.5 \mathrm{~cm}$ diam.), covered with fungal mycelium, were cut from the edge of a 5 -day-old colony and used as an inoculum. All cultures were incubated at $30^{\circ} \mathrm{C}$. There were always five replicates of each treatment.

Alcohol dehydrogenase activity. Sclerotium rolfsii was grown on a cellophane membrane placed on plates of Joham's agar. The mycelium was homogenized with I0 $\mathrm{ml}$ of $0.05 \mathrm{M}$-tris$\mathrm{HCl}$ buffer ( $\mathrm{pH} \mathrm{8.5)} \mathrm{in} \mathrm{an} \mathrm{Omnimixer} \mathrm{(Sorvall)} \mathrm{at} 800 \mathrm{rev} / \mathrm{min}$ for $2 \mathrm{~min}$ and then in an ultrasonic disintegrator (MSE) at $\mathrm{r} \cdot 5 \mathrm{~A}$ for $5 \mathrm{~min}$. Debris was removed by centrifuging at I0000 $\mathrm{g}$ for $15 \mathrm{~min}$. 


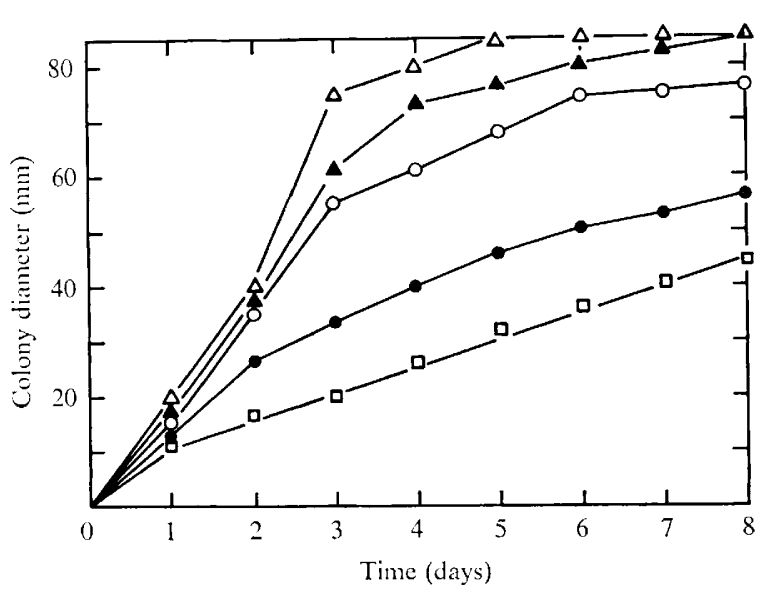

Fig. I

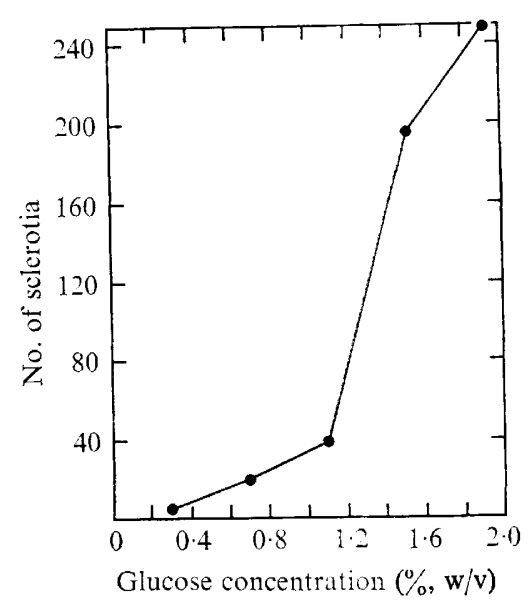

Fig. 2

Fig. I. Effect of glucose concentration on linear growth of mycelium of Sclerotium rolfsii in the presence of $0.5 \%(\mathrm{w} / \mathrm{v})$ lactose. Glucose concentrations $(\%, \mathrm{w} / \mathrm{v}): \triangle-\triangle, \mathrm{I} \cdot 9 ; \boldsymbol{\Delta}-\boldsymbol{\Delta}, \mathbf{I} \cdot 5 ;$ $\mathrm{O}-\mathrm{O}, \mathrm{I} \cdot \mathrm{I} ; 0,0.7 ; \square-\square, 0.3$.

Fig. 2. Effect of glucose concentration on the number of sclerotia formed by Sclerotium rolfsii on a lactose-containing medium. (Lactose concentration, $0.5 \%(\mathrm{w} / \mathrm{v})$; incubation time, 9 days.)

The enzyme was assayed by the method of Zink (1969). Protein content was determined by the method of Lowry, Rosebrough, Farr \& Randall (195I) with bovine albumin as a standard. One unit of enzyme was defined as the amount of enzyme causing a change of 0.001 absorbance units/min. Specific activity was determined as the number of units $/ \mathrm{mg}$ protein in solution.

Saccharomyces oviformis (obtained from the Wine Institute, Rehovot, Israel) was used as a reference organism for the enzyme assay. It was grown for 7 days on yeast dextrose agar (Difco), then harvested and homogenized as already described.

Oxygen uptake. The fungus was grown in $250 \mathrm{ml}$ (Erlenmeyer) flasks containing $75 \mathrm{ml}$ Joham's liquid medium on a shaker (Ioo strokes/min) for 3 days. The mycelium was collected by centrifugation at $800 \mathrm{~g}$ for Io min, then washed five times in $0.0 \mathrm{I} \mathrm{M}$-phosphate buffer $\left(\mathrm{pH}_{7} \cdot \mathrm{O}\right)$, also by centrifugation. Sclerotium rolfsii was starved in the same buffer for $24 \mathrm{~h}$ at $5{ }^{\circ} \mathrm{C}$. Oxygen uptake of $0.2 \mathrm{ml}$ samples containing about $30 \mathrm{mg}$ dry weight was measured in a Gilson differential respirometer (Ioo strokes $/ \mathrm{min}$ ) at $30^{\circ} \mathrm{C}$. The reaction mixture $\left(2.2 \mathrm{ml}\right.$ total volume) contained phosphate buffer $\left(\mathrm{pH}_{7} \cdot 0\right)$, substrates and fungal mycelium.

\section{RESULTS}

Effect of lactose on linear growth and sclerotium formation. The fungus did not grow on the synthetic medium with lactose $(0.5$ to $2 \%, \mathrm{w} / \mathrm{v})$ as the sole carbon source. With glucose $(0.5$ to $2 \%, \mathrm{w} / \mathrm{v})$ as the sole carbon source the fungus grew well and sclerotia began to form after 6 days. When both glucose and lactose were added to the medium sclerotia formed synchronously in a band at the edge of the colony after 4 days. In the medium with $0.5 \%$ lactose, mycelial growth (Fig. I) and the numbers of sclerotia (Fig. 2) increased with glucose concentration and the width of the sclerotial band was directly related to glucose concentration (Fig. 3). Little variation was observed between replicates. 


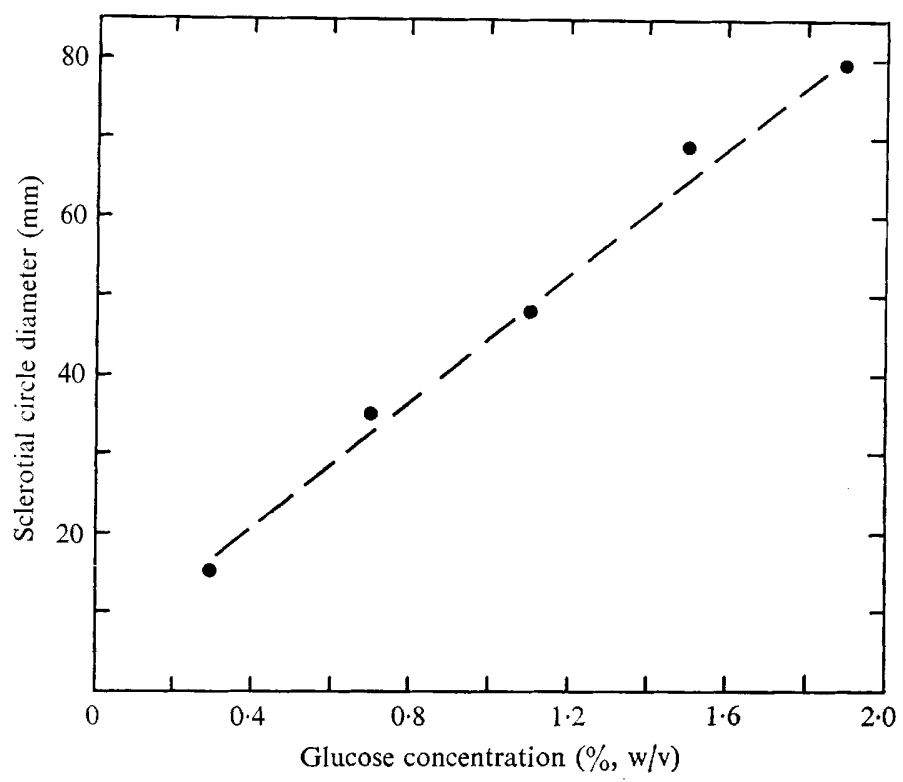

Fig. 3. Effect of glucose concentration on diameter of sclerotial circle on lactose-containing medium.

Inhibition of sclerotial formation by ethanol. Ethanol $(2 \cdot 0$ to $4 \cdot 0 \%, \mathrm{v} / \mathrm{v})$, added to Joham's synthetic medium, temporarily slowed mycelial linear growth and completely inhibited sclerotium formation (Fig. 4, 5).

Ethanol $(2 \%, v / v)$ also inhibited sclerotium formation on Joham's medium supplemented with $5 \times 1 \mathrm{IO}^{-5} \mathrm{M}$-iodoacetic acid which, as previously reported (Chet et al. 1966), induced sclerotia to form in several circles around the point of inoculation. Ethanol also inhibited the synchronous formation of sclerotia on lactose-supplemented media (Fig. 6, 7).

Ethanol dehydrogenase activity in mycelial extract. Alcohol dehydrogenase activity could not be detected in extracts of the fungal mycelium grown for 4 and 14 days on Joham's agar, whereas comparable extracts of 7-day-old cultures of Saccharomyces oviformis showed a specific activity of 350 .

Oxygen uptake. The effects of lactose, ethanol and glucose on respiration of Sclerotium rolfsii are summarized in Fig. 8. Lactose and ethanol were not utilized as sole carbon sources for exogenous respiration. Oxygen uptake with glucose as a substrate was affected by ethanol but not by lactose.

\section{DISCUSSION}

Sugars and sugar alcohols affect differentiation in Physarum polycephalum (Chet \& Rusch, 1969), Myxococcus xantus (Dworkin \& Gibson, 1964) and Sclerotinia sclerotiorum (Liu-Su Chin \& Le Tourneau, 1970). Both timing and location of sclerotial formation in Sclerotium rolfsii could be controlled by changing glucose concentration in lactose-supplemented Joham's media. Chet \& Henis (1968) suggested that sclerotium formation in S. rolfsii was induced by inactivation of a $-\mathrm{SH}-\mathrm{Cu}^{+2}$ protein which acts as a repressor of sclerotium formation. It might be postulated that ethanol could increase the level of - SH groups by entering the metabolic pathway through the -SH-containing alcohol dehydrogenase (Fruton \& Simmonds, 1958). In that case it should not have affected sclerotium formation in the presence of iodoacetic acid (which inhibits alcohol dehydrogenase activity). Furthermore, 

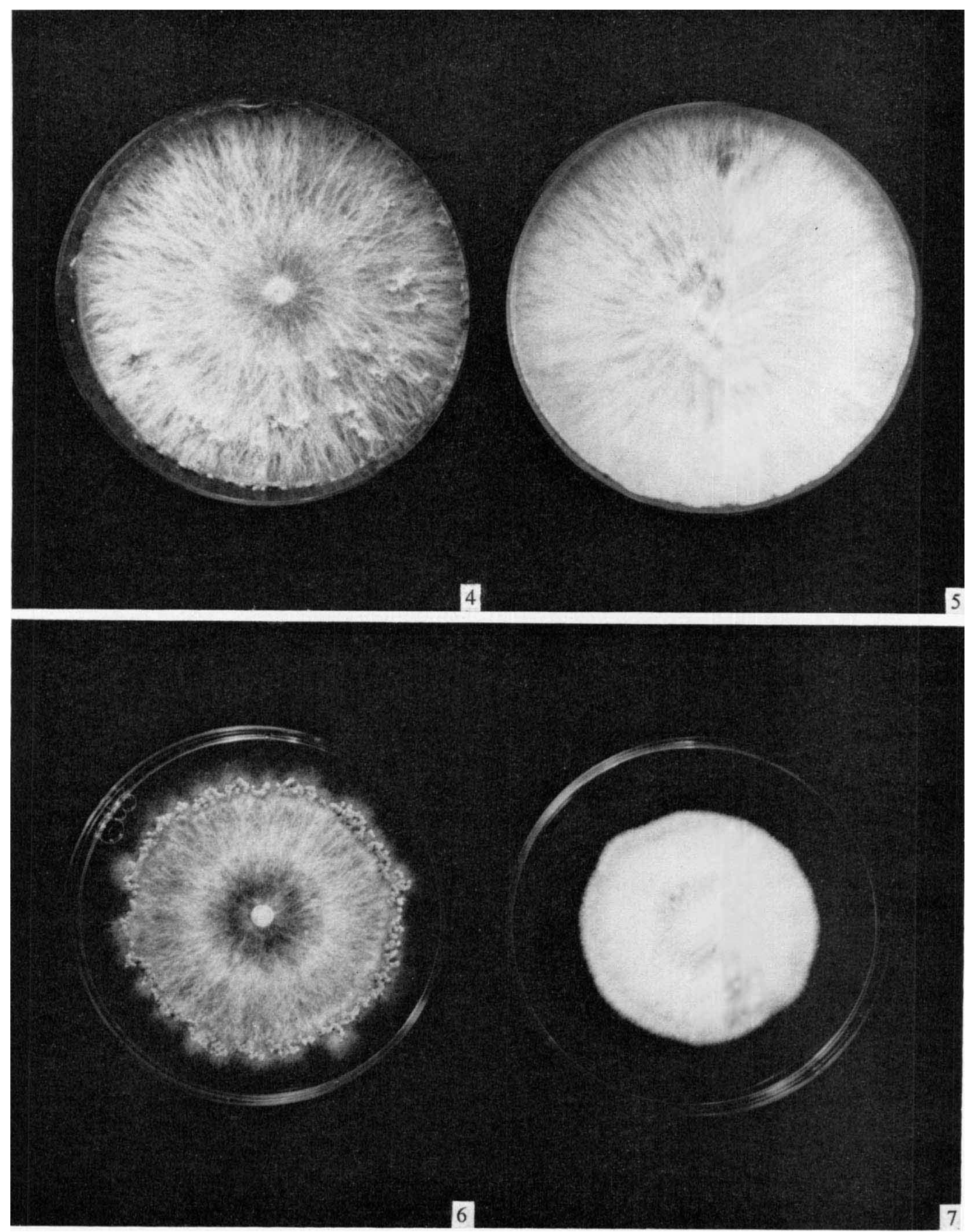

Fig. 4. Sclerotium rolfsii grown on synthetic medium (control).

Fig. 5. Inhibition of sclerotium formation by ethanol $(2 \%, v / v)$.

Fig. 6. Synchronous formation of sclerotia in the presence of lactose $(0.5 \%)$.

Fig. 7. Inhibition of sclerotium formation by ethanol in the presence of lactose $(0.5 \%)$. 


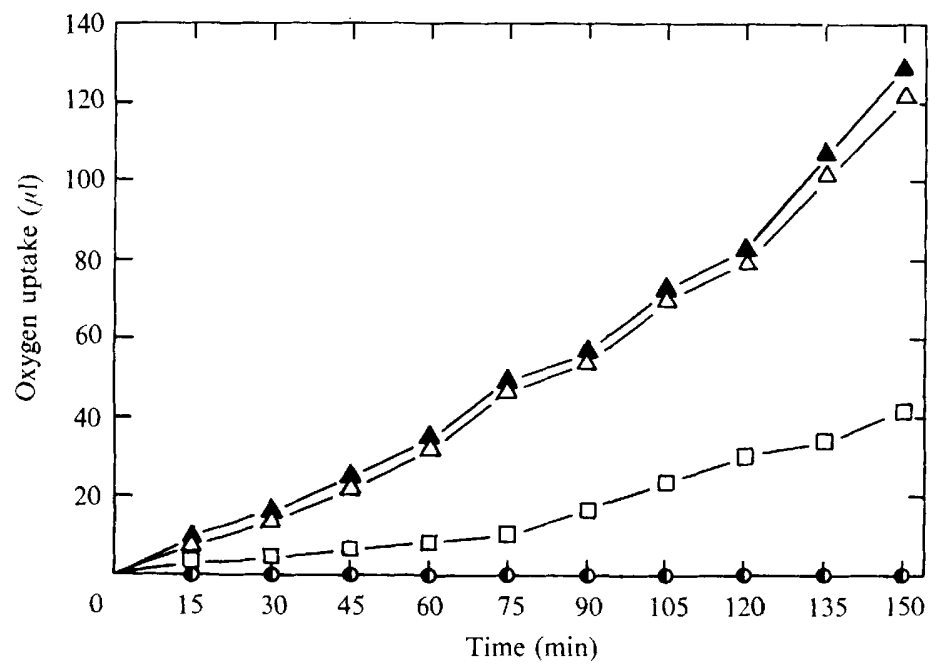

Fig. 8. Respiration of Sclerotium rolfsii on lactose, glucose and ethanol. $\boldsymbol{\Delta}-\boldsymbol{\Delta}, 2 \%$ Glucose; $\triangle-\triangle, 2 \%$ glucose $+2 \%$ lactose; $\square-\square, 2 \%$ glucose $+3 \%$ ethanol; $-0,3 \%$ ethanol; $\mathrm{O}-\mathrm{O}, 2 \%$ lactose.

alcohol dehydrogenase activity was not found in the mycelium, nor could ethanol serve as a substrate for oxygen uptake by $S$. rolfsii.

Another phenomenon which seems incompatible with the sulphydryl hypothesis is the effect of lactose on sclerotium formation. Thus, the $-\mathrm{SH}$ level of the mycelium is probably not the sole factor which directly controls sclerotium formation. A more specific control mechanism of morphogenesis in Sclerotium rolfsii should therefore be sought.

According to Wheeler \& Waller (1965) initiation of sclerotia in Sclerotium rolfsii was regulated by the growing hyphae. They noted that initials did not appear until the lateral extension of mycelium was restricted. Henis et al. (1965) also found that sclerotia were produced along a line cut in the mycelium. Both findings indicate that partial inhibition of linear growth is required for sclerotium formation. However sulphur-containing amino acids (Chet et al. 1966) and ethanol both partially inhibited linear growth of S. rolfsii and also inhibited sclerotium formation. Similarly, cycloheximide inhibited linear growth of $S$. rolfsii when applied in strips or cylinders at colony margin without inducing sclerotium formation (Chet, 1967). Thus, the relationship between partial inhibition of linear growth and sclerotium formation in $S$. rolfsii remains unsolved. Although the modes of action of lactose and ethanol on morphogenesis of $S$. rolfsii are not yet known, this new system of synchronizing and inhibiting formation of sclerotia may prove useful in further studies.

\section{REFERENCES}

CHET, I. (1967). The Structure and Behaviour of the Fungus Sclerotium rolfsii Sacc., p. I2I, Ph.D. Thesis, The Hebrew University of Jerusalem.

CHET, I. \& HenIs, Y. (1968). The control mechanism of sclerotial formation in Sclerotium rolfsii Sacc. Journal of General Microbiology 54, 23 I--235.

Chet, I., Henis, Y. \& Mrtchell, R. (I966). The morphogenetic effect of sulphur-containing amino acids, glutathione and iodoacetic acid on Sclerotium rolfsii Sacc. Journal of General Microbiology 45, 54I-546.

Chet, I. \& Rusch, H. P. (1969). Induction of spherule formation in Physarum polycephalum by polyols. Journal of Bacteriology 100, 673-678.

DWorkin, M. \& Gibson, S. M. (1964). A system for studying microbial morphogenesis: rapid formation of microcyst in Myxococcus xanthus. Science, New York 146, 243-244. 
Fruton, J. S. \& Simmonds, S. (1958). General Biochemistry, pp. 3i6-319. New York: John Wiley \& Sons.

Henis, Y., Chet, I. \& Avizohar-Hershenzon, Z. (1965). Nutritional and mechanical factors involved in mycelial growth and production of sclerotia by Sclerotium rolfsii in artificial medium and amended soil. Phytopathology 55, 87-91.

Joham, M. E. (1943). A Nutritional Study of the Fungus Sclerotium rolfsii. M.Sc. Thesis, A. and M. College of Texas.

LuU-Su-ChIn \& Le Tourneau, D. (1970). Trehalose utilization and sclerotium formation in Sclerotinia sclerotiorum. Phytopathology 6o, 1535 .

Lowry, O. H., Rosebrough, N. J., Farr, A. L. \& Randall, R. J. (195I). Protein measurement with the Folin phenol reagent. Journal of Biological Chemistry I93, 265-275.

WheELer, B. E. J. \& WALler, J. M. (1965). The production of sclerotia by Sclerotium rolfsii. II. The relationship between mycelial growth and initiation of sclerotia. Transactions, British Mycological Society 48, 303-314.

ZrNK, M. W. (1969). Regulation of NAD-specific alcohol dehydrogenase in Neurospora crassa. Canadian Journal of Microbiology 15, 265-27I. 